\title{
Probabilistic Neural Network and Fuzzy Cluster Analysis Methods Applied to Impedance-Based SHM for Damage Classification
}

\author{
Lizeth Vargas Palomino, Valder Steffen Jr., and Roberto Mendes Finzi Neto \\ School of Mechanical Engineering, Federal University of Uberlândia, Campus Santa Mônica, 38400-902 Uberlândia, MG, Brazil \\ Correspondence should be addressed to Valder Steffen Jr.; vsteffen@mecanica.ufu.br
}

Received 10 July 2013; Accepted 20 January 2014; Published 27 May 2014

Academic Editor: Nuno Maia

Copyright (C) 2014 Lizeth Vargas Palomino et al. This is an open access article distributed under the Creative Commons Attribution License, which permits unrestricted use, distribution, and reproduction in any medium, provided the original work is properly cited.

\begin{abstract}
Impedance-based structural health monitoring technique is performed by measuring the variation of the electromechanical impedance of the structure caused by the presence of damage. The impedance signals are collected from patches of piezoelectric material bonded on the surface of the structure (or embedded). Through these piezoceramic sensor-actuators, the electromechanical impedance, which is directly related to the mechanical impedance of the structure, is obtained. Based on the variation of the impedance signals, the presence of damage can be detected. A particular damage metric is used to quantify the damage. Distinguishing damage groups from a universe containing different types of damage is a major challenge in structural health monitoring. There are several types of failures that can occur in a given structure, such as cracks, fissures, loss of mechanical components (e.g., rivets), corrosion, and wear. It is important to characterize each type of damage from the impedance signals considered. In the present paper, probabilistic neural network and fuzzy cluster analysis methods are used for identification, localization, and classification of two types of damage, namely, cracks and rivet losses. The results show that probabilistic neural network and fuzzy cluster analysis methods are useful for identification, localization, and classification of these types of damage.
\end{abstract}

\section{Introduction}

Failures occurring in industrial equipment and structures in general are associated with friction, fatigue, impact, and crack growth or with other reasons. For an appropriate functioning of the system, the failure should be located and repaired timely. In general terms, the problem of damage monitoring consists in locating and measuring the fault and estimating the remaining life of the system (damage prognosis). One of the most important ambitions of modern engineering is to perform structural health monitoring in real time in structural components of high cost and considerable responsibility. Thus, the creation or improvement of techniques that enhance the accuracy and reliability of the tracking process is highly desirable and is the subject of several studies both in industry and academic environments [1].

There are several techniques for monitoring the occurrence and propagation of structural damage. One of these techniques is the so-called impedance-based structural health monitoring [2]. The basic idea behind this technique is monitoring the changes in the mechanical impedance of the structure as caused by the presence of damage. As the direct measurement of the mechanical impedance of the structure is a difficult task, the method uses piezoelectric ceramics (PZT patches) bonded to or incorporated into the structure, allowing the measurement of the electromechanical impedance. As this measure is related to the structure variation of the impedance signals, the presence of damage can be detected. A particular damage metric is used to quantify the damage [3].

The impedance-based SHM technique was first proposed by Liang et al. [4] and subsequently the method was extended by Chaudhry et al. [5, 6], Sun et al. [7], Park et al. [8-11], Giurgiutiu and Zagrai [12], Soh et al. [13], Bhalla et al. [14], Giurgiutiu et al. [15, 16], Moura Jr. and Steffen Jr. [17], Peairs [18], Moura Jr. [19], and Neto et al. [20]. 
Distinguishing damage groups from a universe containing different types of damage is a major challenge in structural health monitoring. There are various types of failures, which may occur in a given structure, such as cracks, fissures, loss of joining components (rivets), corrosion, and wear. In the case of composite structures delamination is a major concern. It is important to characterize each type of damage for defining appropriate correction efforts. In order to distinguish the different damage types, probabilistic neural network and fuzzy cluster analysis methods for classification can be used $[21,22]$.

An artificial neural network is a mathematical model, computational model, or metamodel that mimics the structure by using functional aspects of biological neural networks. It consists of an interconnected group of artificial neurons and processes information by using a connectionist approach for computation [23]. In most cases an artificial neural network is an adaptive system that changes its structure based on external or internal information that flows through the network during the learning phase. Modern neural networks can be understood as nonlinear statistical data modeling tools. They are usually used to model complex relationships between input and output or to find patterns in data [23]. There are several types of artificial neural network; one of them is the probabilistic neural network. This artificial neural network can be used for classification tasks. The network is an implementation of the statistical algorithm called kernel discriminate analysis [24] in which the operations are organized into a multilayered feedforward network with four layers, namely, the input layer, pattern layer, summation layer, and output layer [25].

Fuzzy clustering is an unsupervised learning operation that aims at decomposing a given set of objects into subgroups or clusters based on similarity. The goal is to divide the dataset in such a way that objects or cases belonging to the same cluster are as similar as possible, whereas objects belonging to different clusters are dissimilar [26]. The main potential of clustering is to detect the underlying structure in data, not only for classification and pattern recognition, but also for model reduction and optimization.

In the present paper, the probabilistic neural networks and the fuzzy cluster analysis methods are used for identification, localization, and classification of damage in metallic aeronautic structures. The impedance signal measurement set is used as the input of the probabilistic neural network and the output is the type of damage (crack, rivet loss, or pristine condition). The Gustafson-Kessel fuzzy clustering algorithm was also implemented. The impedance signal measurement set is used as the object to be classified by the fuzzy cluster analysis algorithm and the results represent the type of damage. The results show that the methods are useful for identification, localization, and classification of damage.

1.1. Probabilistic Neural Network. Artificial neural networks are parallel distributed systems composed of simple processing elements (neurons) that calculate given mathematical functions (usually nonlinear). Such units are arranged in one or more layers and interconnected by a large number of connections, usually unidirectional. In most models, these connections are associated with weights, which store the knowledge represented in the model and consider the input received by each neuron in the network. The operation of these networks is inspired by a physical structure designed by nature, the human brain [27]. There are different types of neural networks; the probabilistic neural network is one of them [25].

The probabilistic neural network is predominantly a classifier. It is based on the probability distribution function, and is an implementation of a statistical algorithm known as kernel discriminating analysis [24], in which the operations are organized into a multilayered feedforward network with four layers, namely, the input layer, pattern layer, summation layer, and output layer. The architecture for this system is shown in Figure 1.

When a sample $X$ is presented, the input layer distributes this sample to the pattern layer neurons (second layer). The function described in the following equation is calculated for each $j$-neurons of the $i$-class in the pattern layer:

$$
f t_{i, j}(X)=\frac{1}{(2 \pi)^{d / 2} \sigma_{i}^{d}} \exp \left[\frac{-\left(X-W_{i, j}\right)^{T}\left(X-W_{i, j}\right)}{2 \sigma_{i}^{2}}\right],
$$

where $f t_{i, j}(X)$ is the contribution of the $j$-neuron in the $i$ class; $\sigma$ is the transfer function and $W_{i, j}$ is the weight of the $j$-neuron of the $i$-class. In each $i$-neuron of the summation layer the contribution of each neuron of the pattern layer that belongs to the $i$-class is added. In the output layer, the sample $X$ is associated with the class with the highest probability [25].

The training process consists in a unique step, that is, the weight of each pattern layer neuron is formed by the characteristic vector of each training sample [25].

1.2. Fuzzy Cluster Analysis Method. In clustering analysis the sampled points (or the population) are divided into a quantity of defined groups by using the similarities between these members. In many fields of knowledge, these clustering techniques have been used to distinguish groups by their features [28]. The clustering analyses can be divided into two subclassifications, the hierarchical and nonhierarchical clustering techniques [28]. Both methods considered in the present contribution are nonhierarchical techniques.

The nonhierarchical techniques find directly the $N$ elements of the $k$ clusters or groups in such a way that these partitions follow two criteria, namely, the similarity (or internal cohesion) and separation of the formed groups [28]. The Gustafson-Kessel algorithm is based on the behavior of the objective function. The basic idea considers an objective or evaluation function that assigns to each possible cluster partition a quality or error value that has to be optimized. The optimal solution is the cluster partition that obtains the best evaluation. In this sense, an optimization problem is to be solved when cluster analysis is performed [29]. The corresponding objective function is given by

$$
J=\sum_{i=1}^{k} \sum_{j=1}^{N}\left(u_{i j}\right)^{m} d^{2}\left(x_{j}, v_{i}\right)
$$




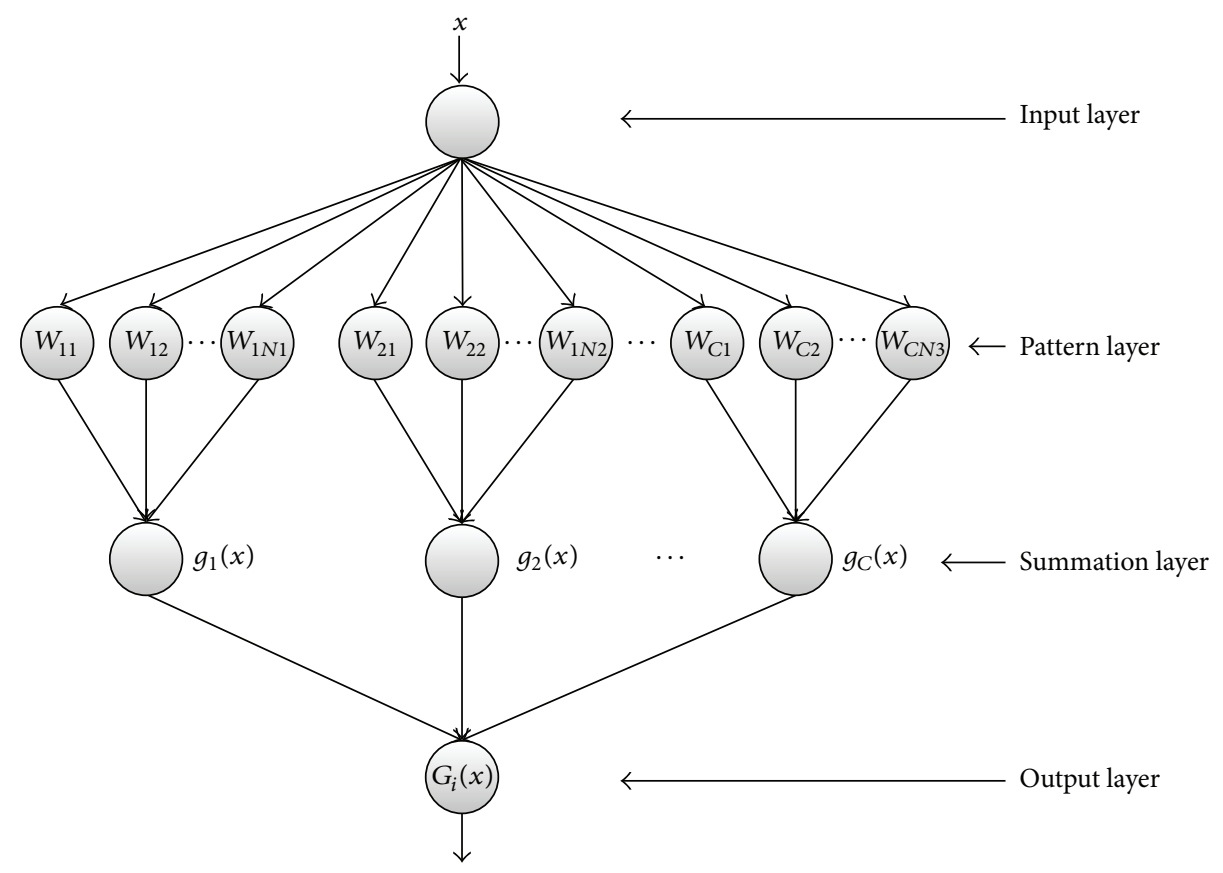

FIgURE 1: Probabilistic neural network architecture.

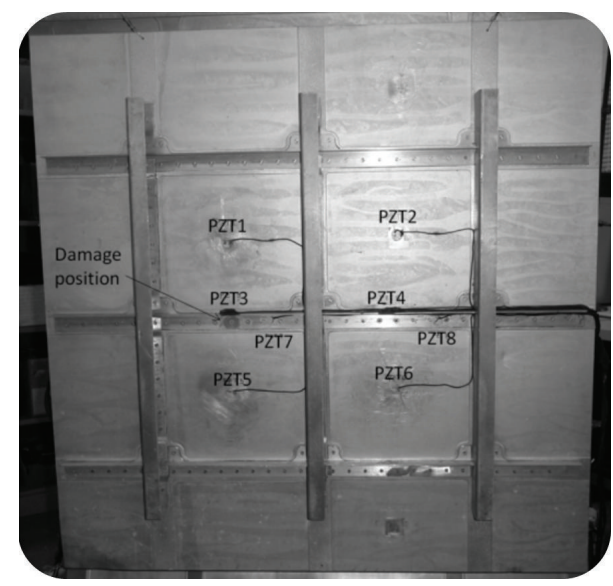

(a)

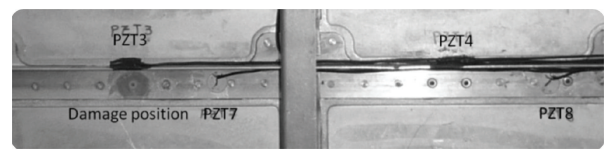

(b)
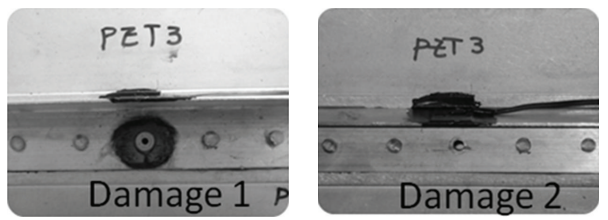

(c)

FIgURE 2: Aluminum aircraft panel equipped with eight PZT patches.

TABLE 1: States of the aircraft panel.

\begin{tabular}{lllc}
\hline Number & State & Description & Measurements number \\
\hline 1 & Baseline & The panel with all rivets & $1-200$ \\
2 & Damage 1 & The panel without one of the rivets (Figure 2(c)) & $201-400$ \\
1 & Baseline & The panel with all rivets & $401-600$ \\
3 & Damage 2 & The panel with all rivets and localized corrosion & $601-800$ \\
\hline
\end{tabular}




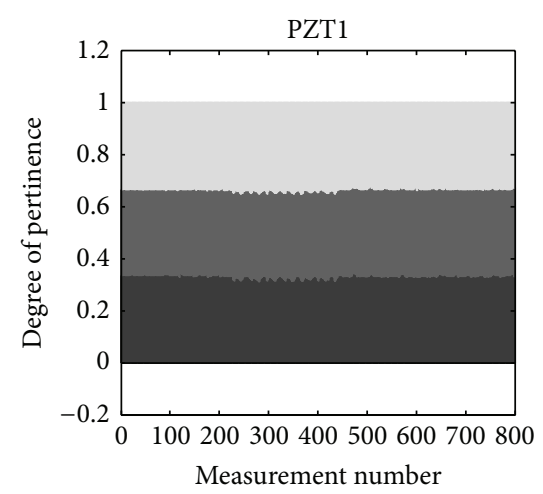

(a)

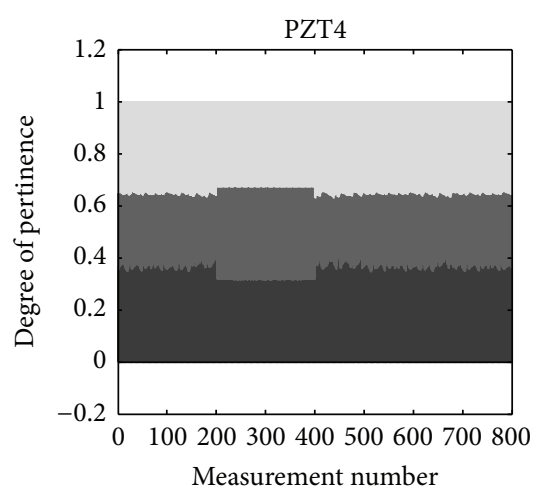

(d)

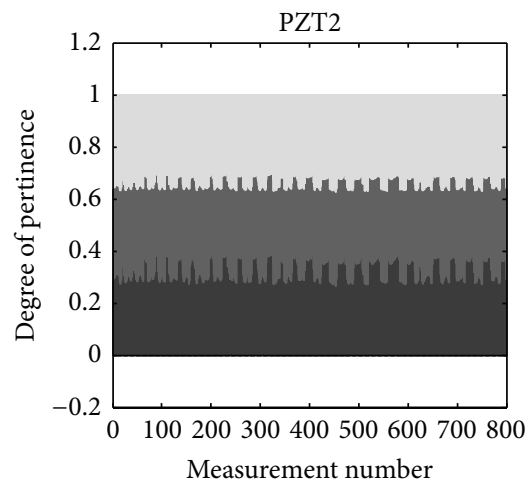

(b)

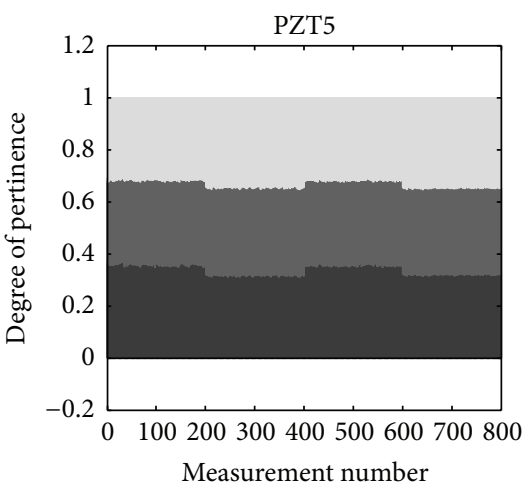

(e)

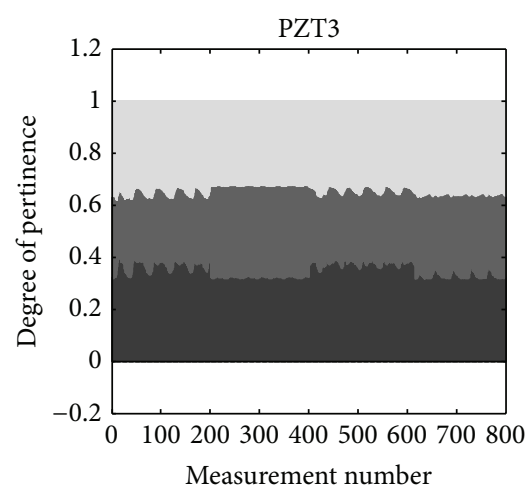

(c)

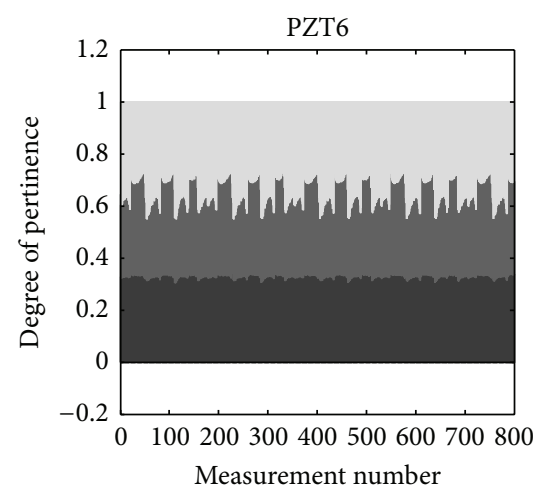

(f)

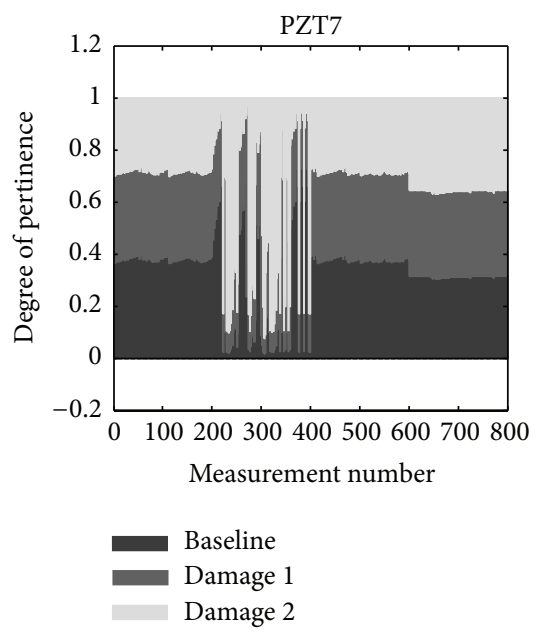

(g)

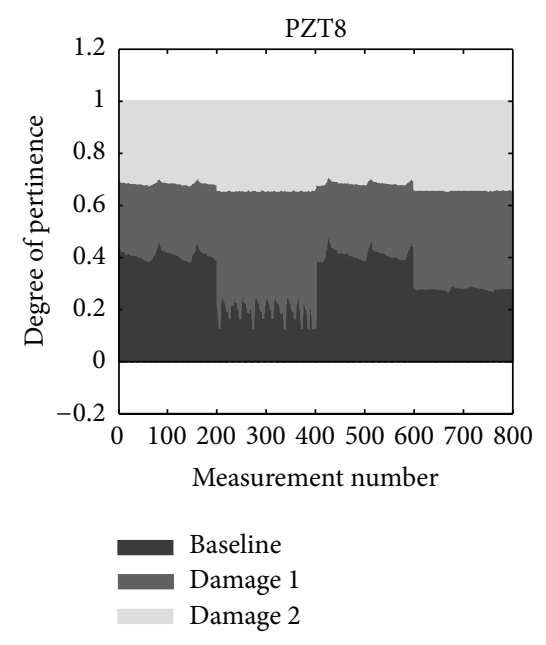

(h)

FIgURE 3: Initial degree of pertinence for aircraft panel.

TABLe 2: Probabilistic neural network for damage classification.

\begin{tabular}{|c|c|c|c|}
\hline Layer & \multicolumn{3}{|c|}{ Number of neurons } \\
\hline Input & \multicolumn{3}{|c|}{190} \\
\hline Pattern & \multicolumn{3}{|c|}{570} \\
\hline Summation & \multicolumn{3}{|c|}{3} \\
\hline \multirow[t]{2}{*}{ Output } & \multicolumn{3}{|c|}{1} \\
\hline & Baseline & Damage 1 & Damage 2 \\
\hline Training set & 360 & 180 & 180 \\
\hline Test set & 40 & 20 & 20 \\
\hline
\end{tabular}




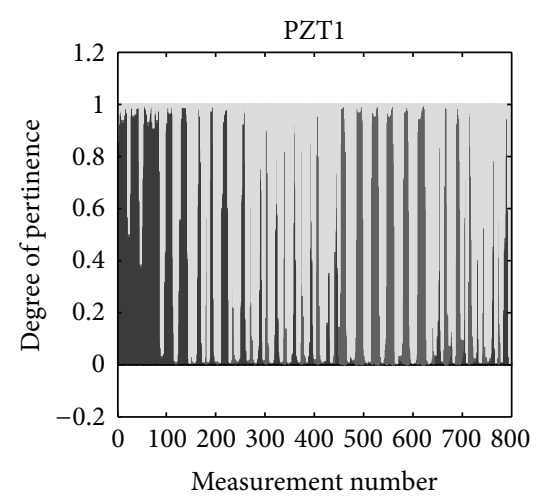

(a)

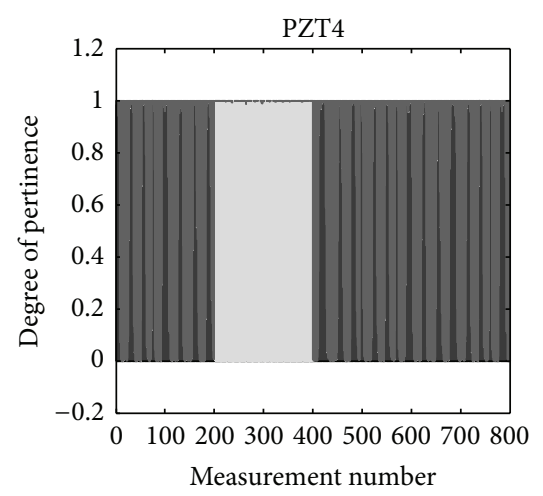

(d)

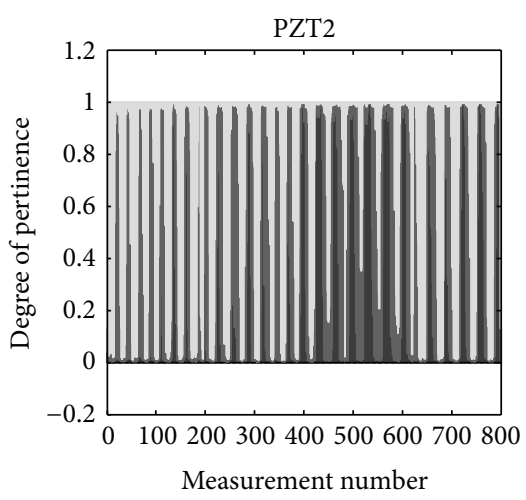

(b)

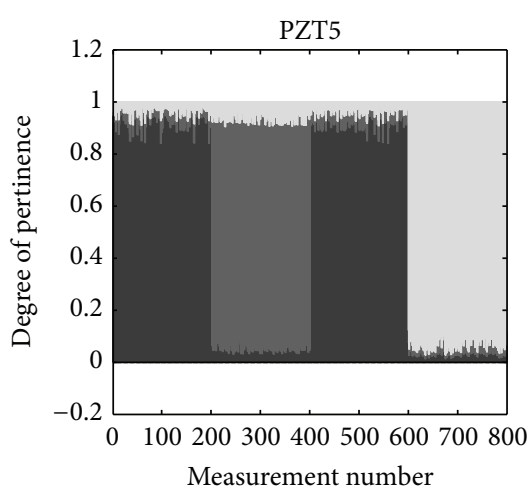

(e)

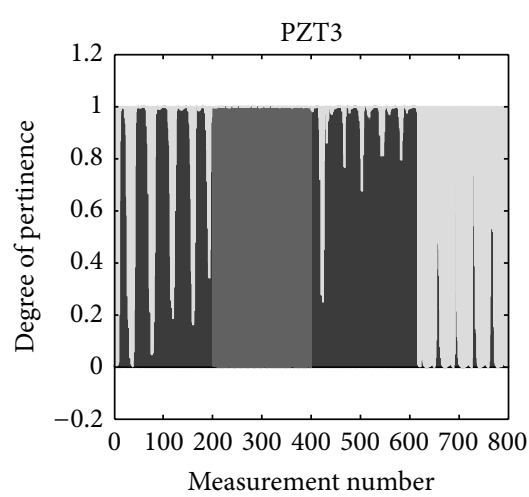

(c)

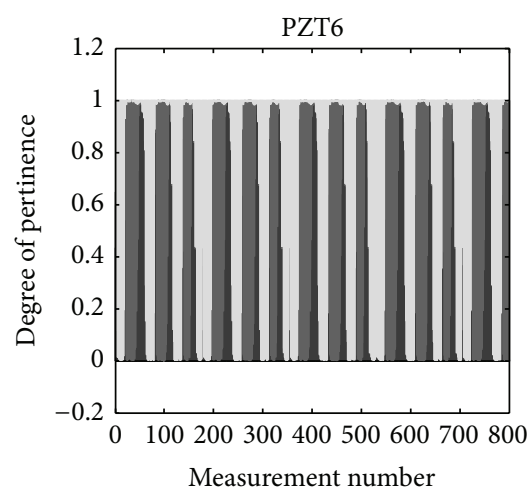

(f)

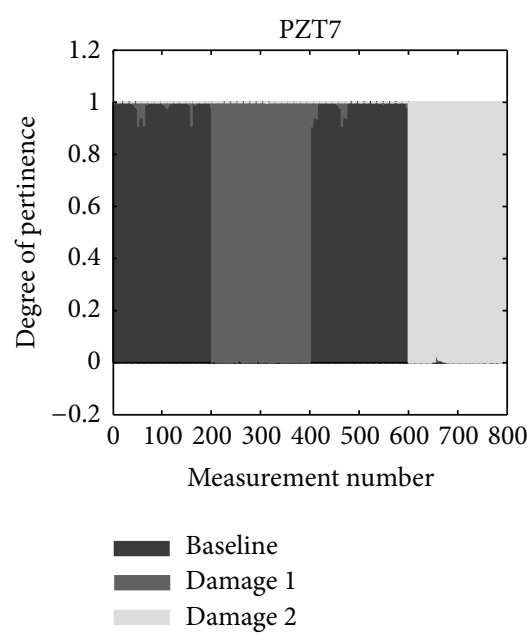

(g)

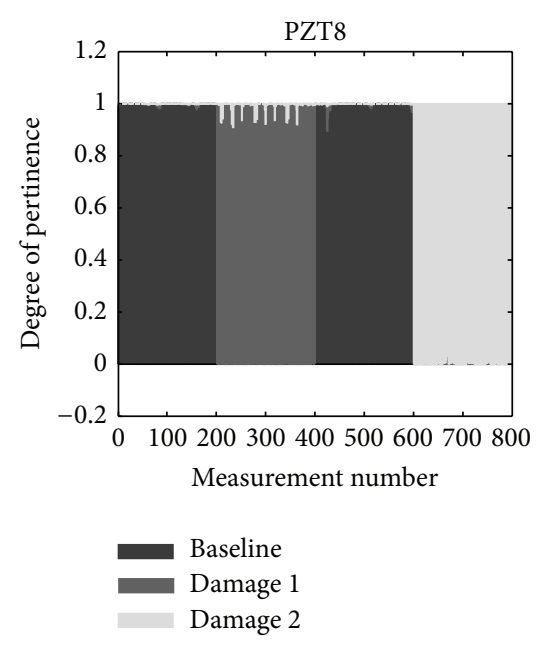

(h)

FIGURE 4: Final degree of pertinence for the aircraft panel.

where $v_{i}$ is the center of the cluster $i, x_{j}$ is the data $j, d\left(x_{j}, v_{i}\right)$ is the distance between $x_{j}$ and cluster center $v_{i}, m$ is the fuzzy parameter, and $u_{i j}$ is the probability of the element $x_{j}$ to pertain to the cluster $i$. The objective function constraints are presented in the following:

$$
\begin{gathered}
0 \leq u_{i j} \leq 1, \\
\sum_{i=1}^{k} u_{i j}=1, \quad \forall j=1, \ldots, N .
\end{gathered}
$$

Mahalanobis distance used in the Gustafson-Kessel (GK) algorithm and the corresponding formulation is presented in the equation below. This technique provides greater flexibility to adapt to the shape and dimensions of each cluster but has higher computational complexity [28]. Consider the following:

$$
d^{2}\left(x_{j}, v_{i}\right)=\left(x_{j}-v_{i}\right)^{T} P_{i}\left(x_{j}-v_{i}\right),
$$




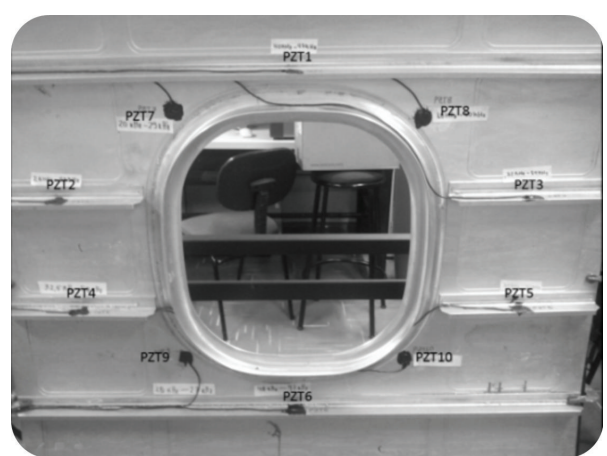

(a)

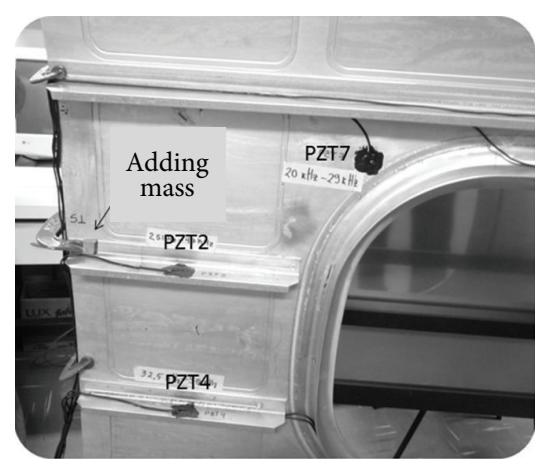

(b)

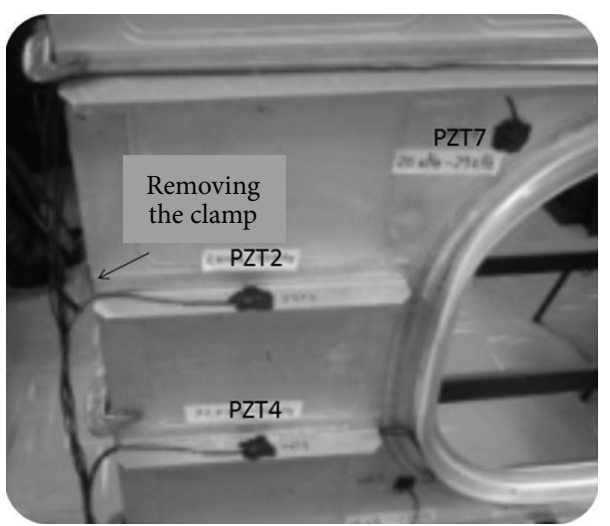

(c)

FIGURE 5: Aluminum aircraft window containing ten PZT patches.

where $P_{i}$ are the fuzzy covariance matrices that are obtained from

$$
P_{i}=\frac{\sum_{j=1}^{N} u_{i j}^{m}\left(x_{j}-v_{i}\right)\left(x_{j}-v_{i}\right)^{T}}{\sum_{j=1}^{N} u_{i j}^{m}} .
$$

The process consists in minimizing the objective function, (4), and the results obtained are the cluster centers $v$ and the pertinence matrix $u$.

\section{Case Study Number 1: Aluminum Aircraft Panel}

The first test presented in this work corresponds to an $80 \times 80 \mathrm{~cm}$ aircraft panel, as shown in Figure 2(a). The structure was tested by using eight PZT patches to capture the impedance signals. A first type of damage was simulated by removing a rivet located close to PZT3, as shown in Figure 2(c). After the measurements have been made for this state, the rivet was reattached at its former position. Then, to simulate a corrosion type of damage, hydrochloric acid was spread in the vicinity of the rivet. A localized corrosion area was obtained (see Figure 2(c)).

A description of each state of the structure is presented in Table 1. Two hundred (200) measurements were taken for each state. Every measured signal contains 200 points.
To classify damage, the impedance signals measured in the panel were used as inputs of the neural networks. Eight probabilistic networks (one for each PZT) were implemented to analyze the structure. All these networks were built with the same architecture, since they were all intended to the same purpose (classifying the damage in the panel). The descriptions of the networks together with their training sets are presented in Table 2 . The results obtained with the test set for each of the eight probabilistic neural networks are presented in Table 3 . The error percentages found in damage classification for PZT1, PZT2, and PZT6 were greater than $48 \%$, which means that they did not detect the damage. The PZT3 and PZT4 showed error percentages greater than 10\%, although it should be noted that the damage 1 (loss of the rivet) was perfectly detected by both of these patches (PZT3 and PZT4). PZT3 and PZT4 were dedicated to this specific damage. The PZT5, PZT7, and PZT8 had error percentages smaller than $4 \%$, similar to the results obtained for simpler structures (beam and plate) [30]. One can thus conclude that these three PZT patches succeeded to properly detect the types of damage that were inserted into the structure.

The initial degrees of pertinence for the Gustafson-Kessel algorithm are shown in Figure 3. After several iterations (Table 4) the algorithm was interrupted by the convergence of the process for every PZT patch that was used. One may then observe the final degree of pertinence as shown in Figure 4. The results of PZT1, PZT2, and PZT6 confirm again that these 
TABLE 3: Classification of test set of probabilistic neural networks for each PZT patch in the aircraft panel.

\begin{tabular}{|c|c|c|c|c|c|}
\hline & & Baseline & Damage 1 & Damage 2 & Error\% \\
\hline \multirow{2}{*}{ PZT1 } & $\checkmark$ & 23 & 10 & 5 & \multirow{3}{*}{$52,5 \%$} \\
\hline & $x$ & 17 & 10 & 15 & \\
\hline Total & & 40 & 20 & 20 & \\
\hline \multirow{2}{*}{ PZT2 } & $\checkmark$ & 20 & 9 & 8 & \multirow{3}{*}{$55 \%$} \\
\hline & $x$ & 20 & 11 & 12 & \\
\hline Total & & 40 & 20 & 20 & \\
\hline \multirow{2}{*}{ PZT3 } & $\checkmark$ & 35 & 20 & 16 & \multirow{3}{*}{$11,25 \%$} \\
\hline & $x$ & 5 & 0 & 4 & \\
\hline Total & & 40 & 20 & 20 & \\
\hline \multirow{2}{*}{ PZT4 } & $\checkmark$ & 32 & 20 & 14 & \multirow{3}{*}{$17,5 \%$} \\
\hline & $x$ & 8 & 0 & 6 & \\
\hline Total & & 40 & 20 & 20 & \\
\hline \multirow{2}{*}{ PZT5 } & $\checkmark$ & 40 & 19 & 18 & \multirow{3}{*}{$3,75 \%$} \\
\hline & $x$ & 0 & 1 & 2 & \\
\hline Total & & 40 & 20 & 20 & \\
\hline \multirow{2}{*}{ PZT6 } & $\checkmark$ & 40 & 20 & 18 & \multirow{3}{*}{$48,75 \%$} \\
\hline & $x$ & 19 & 8 & 12 & \\
\hline Total & & 40 & 20 & 20 & \\
\hline \multirow{2}{*}{ PZT7 } & $\checkmark$ & 40 & 20 & 19 & \multirow{3}{*}{$1,25 \%$} \\
\hline & $x$ & 0 & 0 & 1 & \\
\hline Total & & 40 & 20 & 20 & \\
\hline \multirow{2}{*}{ PZT8 } & $\checkmark$ & 40 & 20 & 18 & \multirow{3}{*}{$2,5 \%$} \\
\hline & $x$ & 0 & 0 & 2 & \\
\hline Total & & 40 & 20 & 20 & \\
\hline
\end{tabular}

TABLE 4: Optimization results of the Gustafson-Kessel algorithm for the aircraft panel.

\begin{tabular}{lccc}
\hline & Iteration & Initial objective function value & Final objective function value \\
\hline PZT1 & 139 & 3173,262 & 446,395 \\
PZT2 & 102 & 831,342 & 118,823 \\
PZT3 & 67 & 532244,526 & 5803,566 \\
PZT4 & 47 & 602945,975 & 2788,759 \\
PZT5 & 18 & 186,055 & 95,991 \\
PZT6 & 131 & 3644,445 & 1594,554 \\
PZT7 & 13 & 1041994,032 & 23013,747 \\
PZT8 & 25 & 1452335,476 & 10885,113 \\
\hline
\end{tabular}

PZTs failed to detect damage and thus made the classification impossible. The PZT3 and PZT4 correctly identified the damage 1; nevertheless the damage 2 was impossible to be distinguished from the Baseline. Finally, the PZT5, PZT7, and PZT8 managed to correctly classify the two types of damage with a degree of pertinence greater than $80 \%$.

\section{Case Study Number 2: Aluminum Aircraft Window}

A second aircraft structure was used to test the artificial intelligence techniques in structural health monitoring for damage classification. For this aim a window located in an aluminum aircraft structure, as illustrated in Figure 5(a), was used. Due to the size and complexity of the structure, ten PZT patches were considered in the experiment. This number of PZT patches was arbitrary since no preliminary study was performed to optimize the test configuration. Since the beginning of the tests, the PZT10 showed poor stability and repeatability and has therefore been ignored in the test. To simulate two different types of damage in the structure, two experiments were performed as follows. First, a weight was added to the structure as shown in Figure 5(b). Second, after the mentioned weight was removed, one of the clamps (located close to the PZT2) was removed (Figure 5(c)). For every state of the structure 200 measurements were made as shown in Table 5. For every measurement 200 points were taken. 
TABLE 5: States of the aircraft window.

\begin{tabular}{lclc}
\hline Number & State & Description & Measurements number \\
\hline 1 & Baseline & Window with all the clamps & $1-200$ \\
2 & Damage 1 & Window with all the clamps and the weight & $201-400$ \\
1 & Baseline & Window with all the clamps & $401-600$ \\
3 & Damage 2 & Window with one clamp missing near PZT2 (Figure 5(c)) & $601-800$ \\
\hline
\end{tabular}

TABLE 6: Classification of test set of probabilistic neural networks for each PZT patch of the aircraft window.

\begin{tabular}{|c|c|c|c|c|c|}
\hline & & Baseline & Damage 1 & Damage 2 & Error\% \\
\hline \multirow{2}{*}{ PZT1 } & $\checkmark$ & 21 & 8 & 12 & \multirow{3}{*}{$48,75 \%$} \\
\hline & $x$ & 19 & 12 & 8 & \\
\hline Total & & 40 & 20 & 20 & \\
\hline \multirow{2}{*}{ PZT2 } & $\checkmark$ & 36 & 16 & 20 & \multirow{3}{*}{$10 \%$} \\
\hline & $x$ & 4 & 4 & 0 & \\
\hline Total & & 40 & 20 & 20 & \\
\hline \multirow{2}{*}{ PZT3 } & $\checkmark$ & 20 & 3 & 7 & \multirow{3}{*}{$62,5 \%$} \\
\hline & $x$ & 20 & 17 & 13 & \\
\hline Total & & 40 & 20 & 20 & \\
\hline \multirow{2}{*}{ PZT4 } & $\checkmark$ & 19 & 7 & 13 & \multirow{3}{*}{$51,25 \%$} \\
\hline & $x$ & 21 & 13 & 7 & \\
\hline Total & & 40 & 20 & 20 & \\
\hline \multirow{2}{*}{ PZT5 } & $\checkmark$ & 21 & 8 & 13 & \multirow{3}{*}{$47,5 \%$} \\
\hline & $x$ & 19 & 12 & 7 & \\
\hline Total & & 40 & 20 & 20 & \\
\hline \multirow{2}{*}{ PZT6 } & $\checkmark$ & 17 & 9 & 9 & \multirow{3}{*}{$56,25 \%$} \\
\hline & $x$ & 23 & 11 & 11 & \\
\hline Total & & 40 & 20 & 20 & \\
\hline \multirow{2}{*}{ PZT7 } & $\checkmark$ & 40 & 19 & 20 & \multirow{3}{*}{$1,25 \%$} \\
\hline & $x$ & 0 & 1 & 0 & \\
\hline Total & & 40 & 20 & 20 & \\
\hline \multirow{2}{*}{ PZT8 } & $\checkmark$ & 33 & 15 & 20 & \multirow{3}{*}{$18,75 \%$} \\
\hline & $x$ & 7 & 8 & 0 & \\
\hline Total & & 40 & 20 & 20 & \\
\hline \multirow{2}{*}{ PZT9 } & $\checkmark$ & 33 & 15 & 20 & \multirow{3}{*}{$11,25 \%$} \\
\hline & $x$ & 7 & 5 & 0 & \\
\hline Total & & 40 & 20 & 20 & \\
\hline
\end{tabular}

TABLE 7: Optimization results of the Gustafson-Kessel algorithm for the aircraft window.

\begin{tabular}{lccc}
\hline & Iteration & Initial objective function value & Final objective function value \\
\hline PZT1 & 130 & 107992,545 & 13922,783 \\
PZT2 & 44 & 1951882,844 & 3723,708 \\
PZT3 & 112 & 11418,915 & 1011,319 \\
PZT4 & 131 & 14063,77 & 1106,733 \\
PZT5 & 105 & 73130,147 & 3914,543 \\
PZT6 & 83 & 187017,9 & 8330,349 \\
PZT7 & 9 & 209498,097 & 1474,566 \\
PZT8 & 101 & 71861,057 & 7189,752 \\
PZT9 & 40 & 149831,047 & 652,42 \\
\hline
\end{tabular}




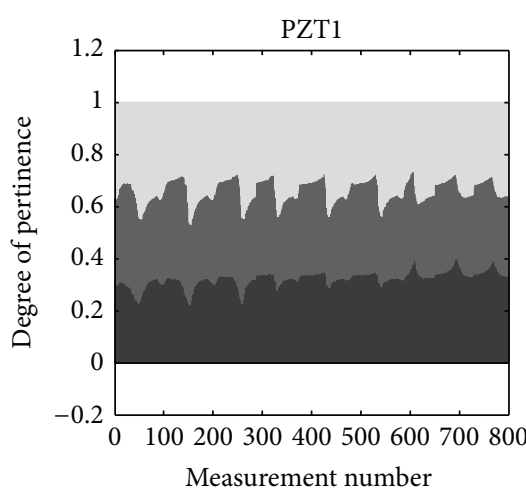

(a)

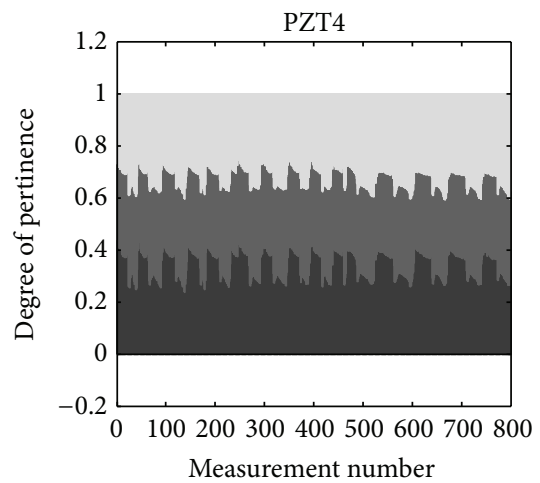

(d)

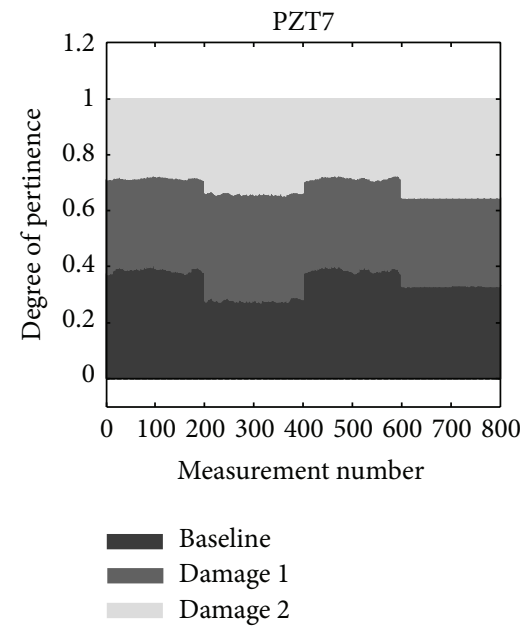

(g)

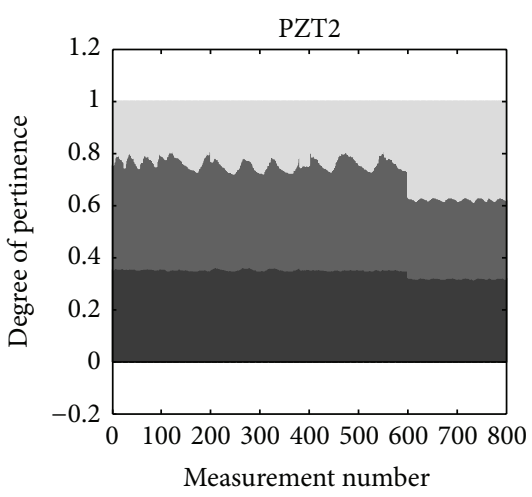

(b)

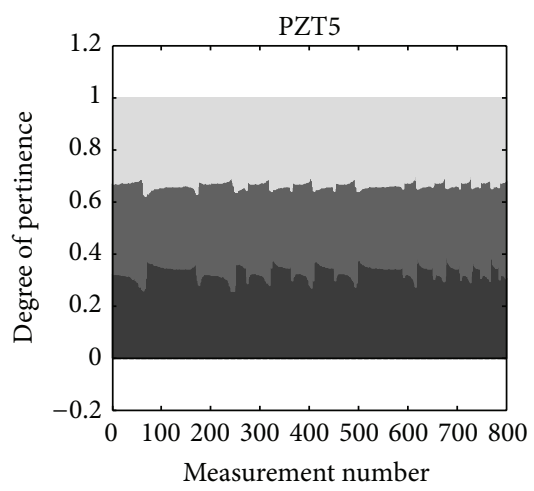

(e)

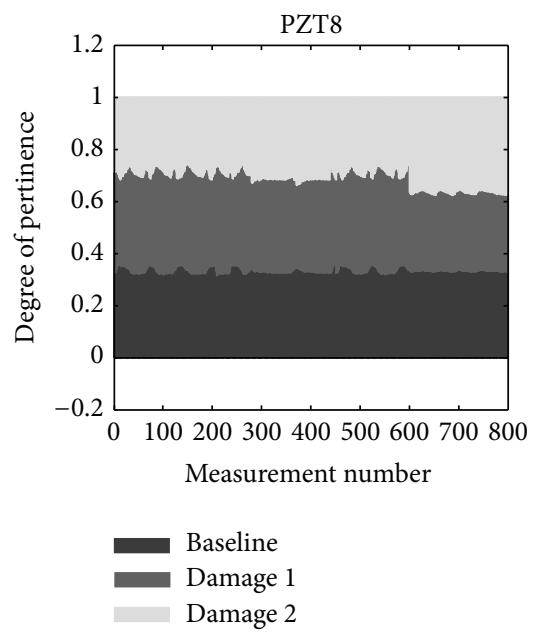

(h)

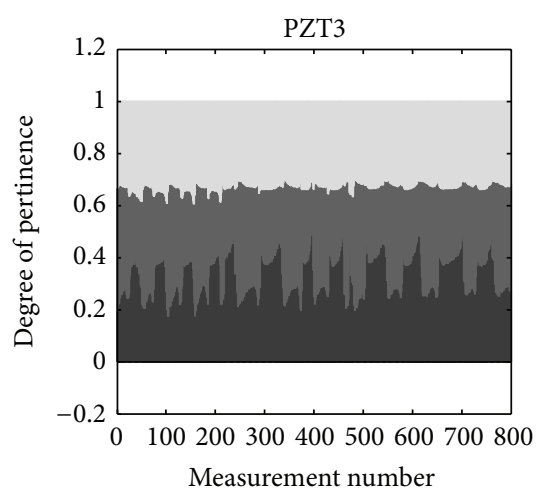

(c)

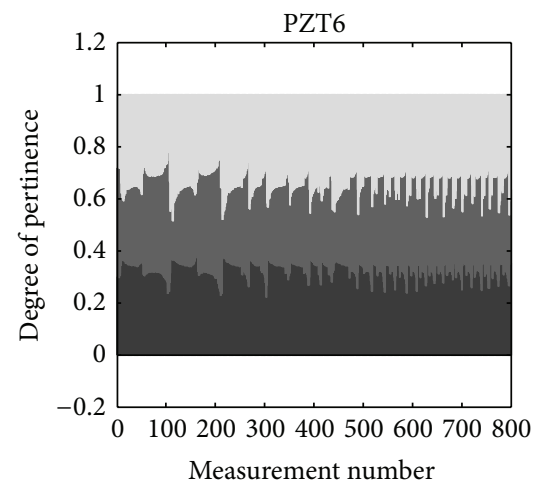

(f)

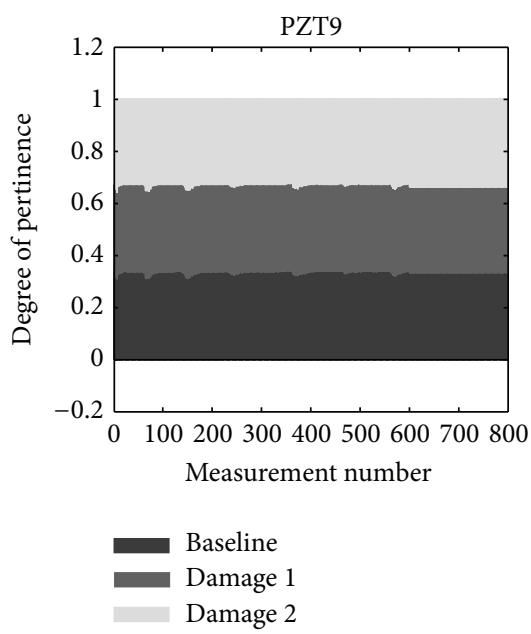

(i)

Figure 6: Initial degrees of pertinence for the aircraft window.

In this case, nine probabilistic networks were implemented (one for each PZT) to analyze this structure as shown in Table 2. The results obtained with the test set for each one of the nine probabilistic neural networks are presented in Table 6.

The damage misclassification percentages of PZT1, PZT3, PZT4, PZT5, and PZT6 were greater than 48\%. These PZT patches are not meant to detect damage. The types of damage (structural modifications in this case) were inserted in the back panel and the PZT patches were bonded to the reinforcing beams. The PZT2, while installed in a reinforcement beam, was able to detect the damage 2 without errors; this success is due to the fact that this sensor is close to the clamp position. The PZT8 and PZT9 detected only the clamp removal without errors, with an overall error percentage of less than 20\%. Finally, the PZT7, which was bonded directly onto the panel and close to the removed clamp, was able to identify all states with an error percentage of $1.25 \%$.

The initial degrees of pertinence for the Gustafson-Kessel algorithm are shown in Figure 6. After several iterations (Table 7), the algorithm was interrupted by the convergence of the process for each of the PZT patches. The final degrees 


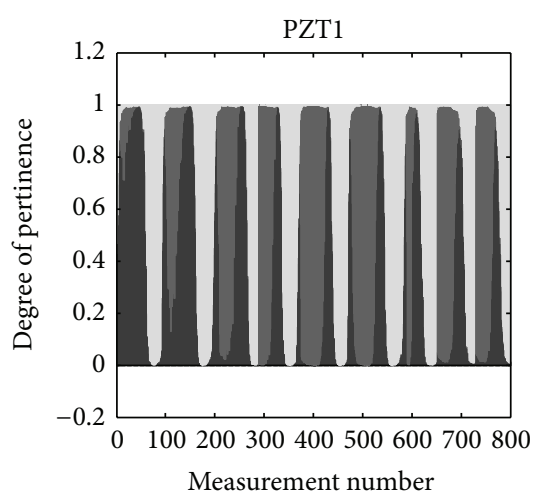

(a)

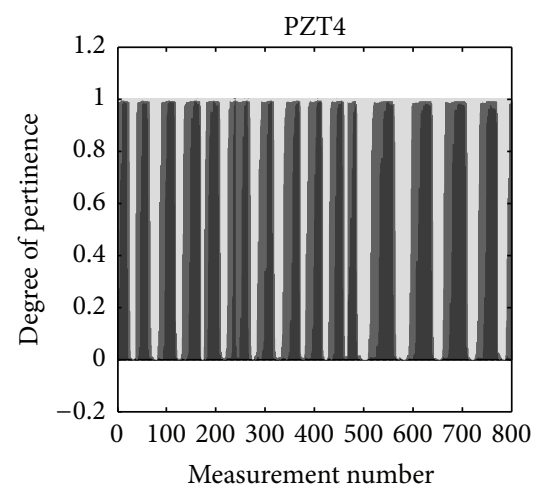

(d)

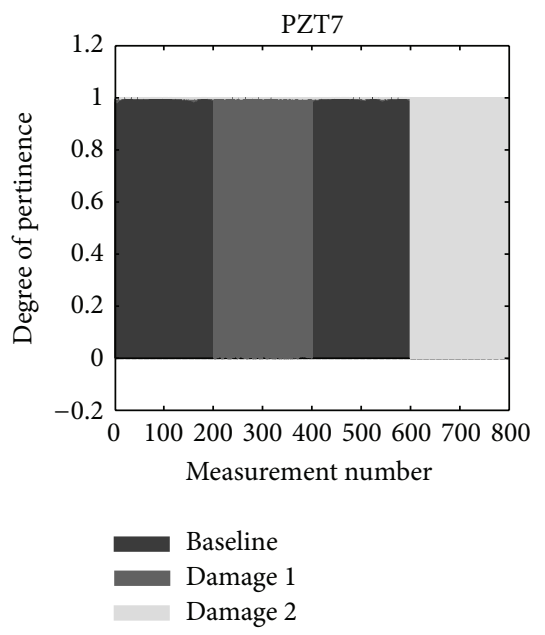

(g)

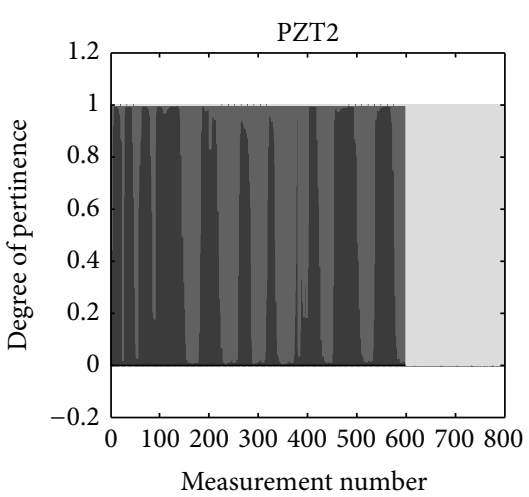

(b)

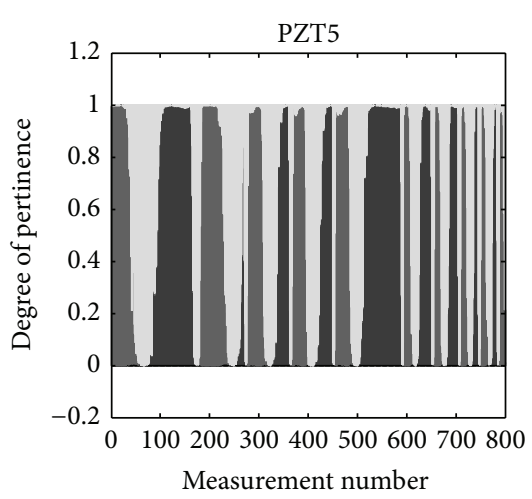

(e)

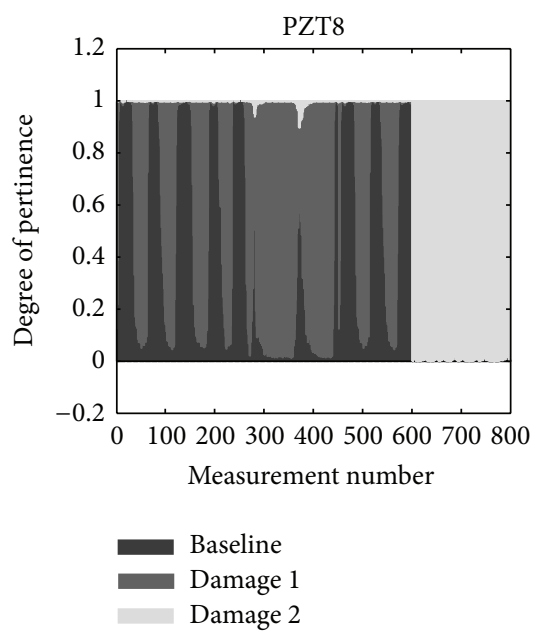

(h)

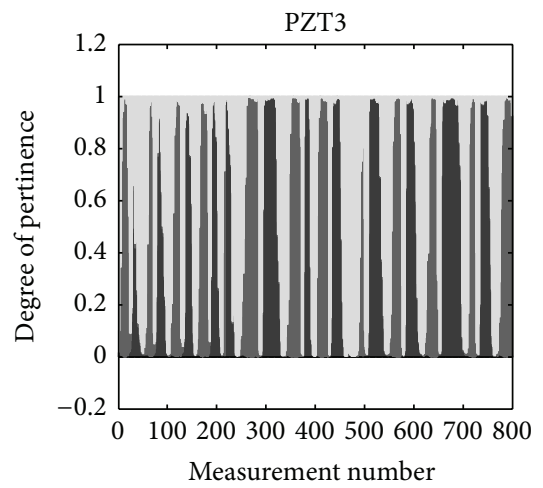

(c)

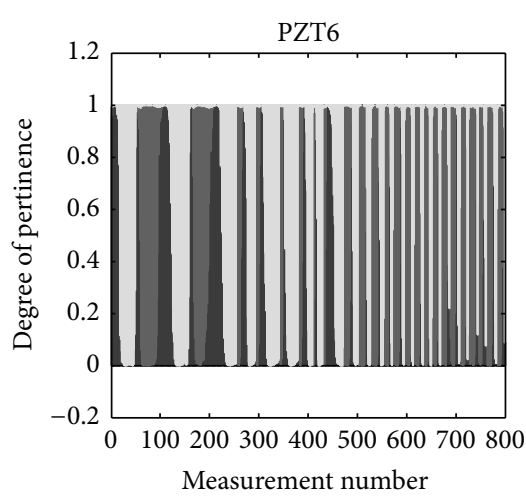

(f)

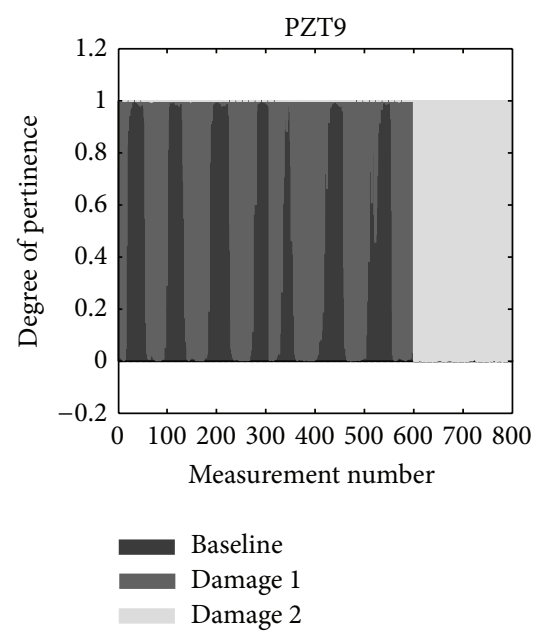

(i)

FIGURE 7: Final degrees of pertinence for the aircraft window.

of pertinence are shown in Figure 7. The results of the PZT1, PZT3, PZT4, PZT5, and PZT6 confirm once again that these PZT patches failed to detect damage, which made the classification impossible due to the position of the patches on the structure. The PZT2, PZT8, and PZT9 correctly classified damage 2, with a degree of pertinence of $99 \%$. However, the damage 1 was impossible to discriminate from the baseline. Finally, for the PZT7, the Gustafson-Kessel algorithm was able to correctly classify all measurements with a degree of pertinence greater than $95 \%$.

\section{Conclusion}

The probabilistic neural network and fuzzy cluster analysis methods were applied to real-world structures in the context of impedance-based structural health monitoring for damage detection, localization, and classification purposes in metallic aeronautic structures. Impedance signal responses were used as the input of the probabilistic neural network. The output was the type of damage (crack, rivet loss, or pristine condition). The Gustafson-Kessel fuzzy clustering algorithm was 
also implemented. The results demonstrated the efficiency of these techniques in accomplishing these tasks. It should be pointed out that the tests were performed at constant room temperature (approximately $20^{\circ} \mathrm{C}$ ). The PZT patches that presented the largest error percentages for both techniques used were the ones that did not succeed to detect damage due to their inappropriate location along the structure [30]. This means that the location of the PZT patches is a major concern in impedance-based structural health monitoring. Further studies will focus on temperature compensation regarding its influence on the damage classification approach. Also, the authors have designed a compact network signal analyzer for electromechanical impedance measurements, which includes post-processing computation for damage metrics calculation and temperature compensation, aiming at on board/online structural health monitoring.

\section{Conflict of Interests}

The authors declare that there is no conflict of interests regarding the publication of this paper.

\section{Acknowledgments}

The authors are thankful to FAPEMIG (TEC-APQ-00076-09) and CNPq (Proc. Nb. 574001/2008-5), research agencies in Brazil, for providing financial support to this work through the INCT-EIE.

\section{References}

[1] C. R. Farrar, N. A. J. Lieven, and M. T. Bement, "An introduction to damage prognosis," in Damage Prognosis for Aerospace, Civil and Mechanical System, chapter 1, Wiley, New York, NY, USA, 2005.

[2] G. Park and D. J. Inman, "Impedance-based structural health monitoring," in Damage Prognosis for Aerospace, Civil and Mechanical System, chapter 13, Wiley, New York, NY, USA, 2005.

[3] L. V. Palomino and V. Steffen, "Damage metrics associated with electromechanical Impedance technique for SHM applied to a riveted structure," in Proceedings of the 20th International Congress of Mechanical Engineering (COBEM '09), Gramado, Brazil, 2009.

[4] C. Liang, F. P. Sun, and C. A. Rogers, "Coupled electro-mechanical analysis of adaptive material systems-determination of the actuator power consumption and system energy transfer," Journal of Intelligent Material Systems and Structures, vol. 5, no. 1, pp. 12-20, 1994.

[5] Z. A. Chaudhry, T. Joseph, F. P. Sun, and C. A. Rogers, "Local-area health monitoring of aircraft via piezoelectric actuator/sensor patches," in Smart Structures and Materials: Smart Structures and Integrated Systems, Proceedings of SPIE, pp. 268276, San Diego, Calif, USA, March 1995.

[6] Z. Chaudhry, F. Lalande, A. Ganino, C. A. Rogers, and J. Chung, "Monitoring the integrity of composite patch structural repair via piezoelectric actuators/sensors," in Proceedings of the 36th AIAA/ASME/ASCE/AHS/ASC Structures, Structural Dynamics, and Materials Conference and AIAA/ASME Adaptive Structures Forum, pp. 2243-2248, April 1995.
[7] F. P. Sun, Z. Chaudhry, C. Liang, and C. A. Rogers, "Truss structure integrity identification using PZT sensor-actuator," Journal of Intelligent Material Systems and Structures, vol. 6, no. 1, pp. 134-139, 1995.

[8] G. Park, K. Kabeya, H. H. Cudney, and D. J. Inman, "Impedance-based structural health monitoring for temperature varying applications," JSME International Journal, Series A: Mechanics and Material Engineering, vol. 42, no. 2, pp. 249-258, 1999.

[9] G. Park, H. H. Cudney, and D. J. Inman, "An integrated health monitoring technique using structural impedance sensors," Journal of Intelligent Material Systems and Structures, vol. 11, no. 6, pp. 448-455, 2000.

[10] G. Park, H. H. Cudney, and D. J. Inman, "Feasibility of using impedance-based damage assessment for pipeline structures," Earthquake Engineering and Structural Dynamics, vol. 30, no. 10, pp. 1463-1474, 2001.

[11] G. Park, H. Sohn, C. R. Farrar, and D. J. Inman, "Overview of piezoelectric impedance-based health monitoring and path forward," Shock and Vibration Digest, vol. 35, no. 6, pp. 451-463, 2003.

[12] V. Giurgiutiu and A. N. Zagrai, "Characterization of piezoelectric wafer active sensors," Journal of Intelligent Material Systems and Structures, vol. 11, no. 12, pp. 959-976, 2001.

[13] C. K. Soh, K. K.-H. Tseng, S. Bhalla, and A. Gupta, "Performance of smart piezoceramic patches in health monitoring of a RC bridge," Smart Materials and Structures, vol. 9, no. 4, pp. 533-542, 2000.

[14] S. Bhalla, A. S. K. Naidu, C. Wee Ong, and C.-K. Soh, "Practical issues in the implementation of electro-mechanical impedance technique for NDE," in Smart Structures, Devices, and Systems, Proceedings of SPIE, pp. 484-494, Melbourne,Australia, December 2002.

[15] V. Giurgiutiu, A. Zagrai, and J. J. Bao, "Piezoelectric wafer embedded active sensors for aging aircraft structural health monitoring," Structural Health Monitoring, vol. 1, no. 1, pp. 4161, 2002.

[16] V. Giurgiutiu, A. Zagrai, J. J. Bao, J. M. Redmond, D. Roach, and K. Rackow, "Active sensors for health monitoring of aging aerospace structures," International Journal of the Condition Monitoring and Diagnostic Engineering Management, vol. 6, no. 1, pp. 3-21, 2003.

[17] J. R. V. Moura Jr. and V. Steffen Jr, "Impedance-based health monitoring: frequency band evaluation," in XXII IMAC, Dearborn, Mich, USA, 2004.

[18] M. D. Peairs, High frequency modeling and experimental analysis for implementation of impedance-based structural health monitoring [Ph.D. thesis], Virginia Polytechnic Institute and State University, Blacksburg, Va, USA, 2006.

[19] J. R. V. Moura Jr., Contribution to structural health monitoring systems applied to aeronautic and space structures [Ph.D. thesis], Universidade Federal de Uberlândia, Uberlandia, Brazil, 2008.

[20] R. M. Neto, V. Steffen Jr., D. A. Rade, C. A. Gallo, and L. V. Palomino, "A low-cost electromechanical impedancebased shm architecture for multiplexed piezoceramic actuators," Structural Health Monitoring, vol. 10, no. 4, pp. 391-402, 2011.

[21] R. R. K. Reddy and R. Ganguli, "Structural damage detection in a helicopter rotor blade using radial basis function neural networks," Smart Materials and Structures, vol. 12, no. 2, pp. 232-241, 2003. 
[22] P. M. Pawar and R. Ganguli, "Genetic fuzzy system for damage detection in beams and helicopter rotor blades," Computer Methods in Applied Mechanics and Engineering, vol. 192, no. 1618, pp. 2031-2057, 2003.

[23] J. G. Taylor, "Neural network applications," in Proceedings of the 2nd British Neural Network Society Meeting (NCM '91), Springer, London, UK, 1992.

[24] M. Rosenblatt, "Remarks on some non parametric estimates of a density function," Annals of Mathematical Statistics, vol. 27, pp. 832-837, 1956.

[25] D. F. Specht, "Probabilistic neural networks," Neural Networks, vol. 3, no. 1, pp. 109-118, 1990.

[26] R. Kruse, C. Doring, and M. J. Lesot, "Fundamentals of fuzzy clustering," in Advances in Fuzzy Clustering and Its Applications, Chapter 1, pp. 3-30, Wiley, New York, NY, USA, 2007.

[27] A. P. Braga, A. P. L. F. Carvalho, and T. B. Ludermir, Redes Neurais Artificiais Teoria e Aplicacoes, LTC, Rio de Janeiro, Brazil, 2000.

[28] S. A. Mingoti, Análise de Dados Através de Métodos de Estatística Multivariada, Editora UFMG, Belo Horizonte, Brazil, 2005.

[29] F. Hoppner, F. Klawonn, R. Kruse, and T. Runkler, Fuzzy Cluster Analysis, Wiley, New York, NY, USA, 1999.

[30] L. V. Palomino, Artificial intelligence techniques applied to the impedance-based structural health monitoring technique for monitoring damage in aircraft structures [Ph.D. thesis], Federal University of Uberlândia, Uberlândia, Brazil, 2012. 

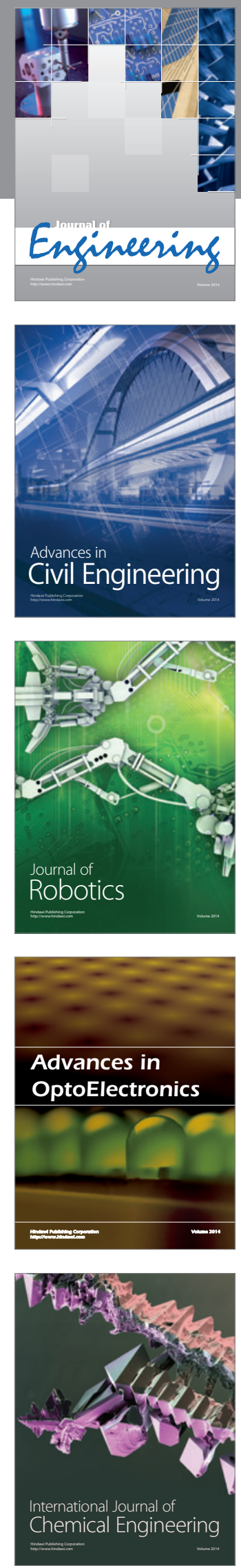

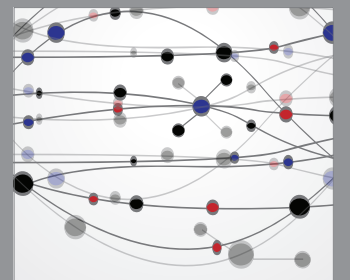

The Scientific World Journal
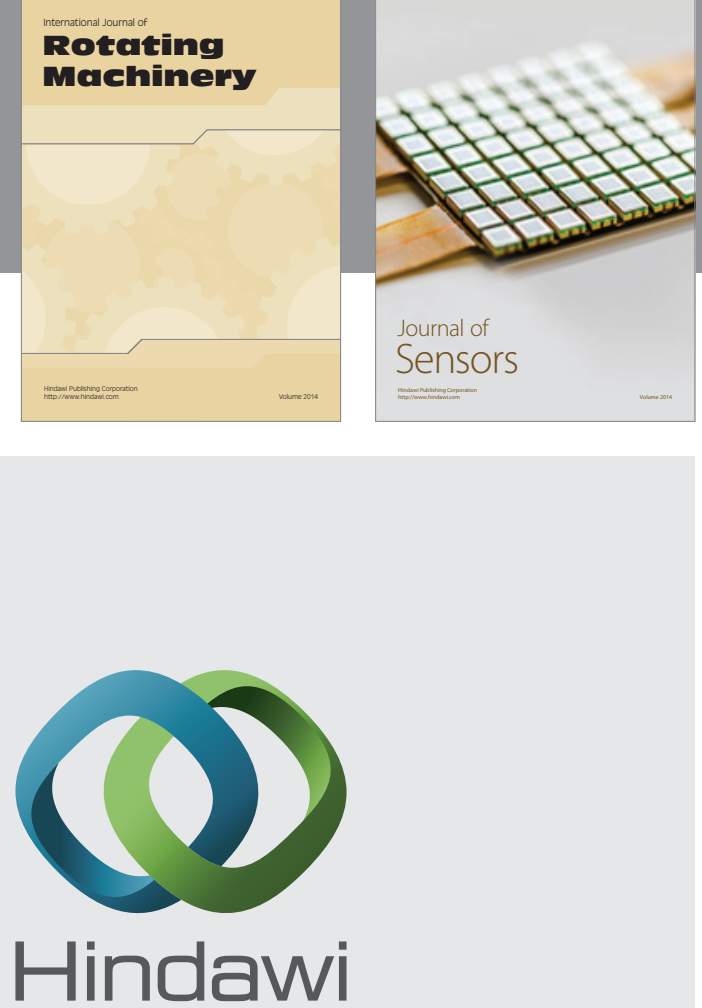

Submit your manuscripts at http://www.hindawi.com
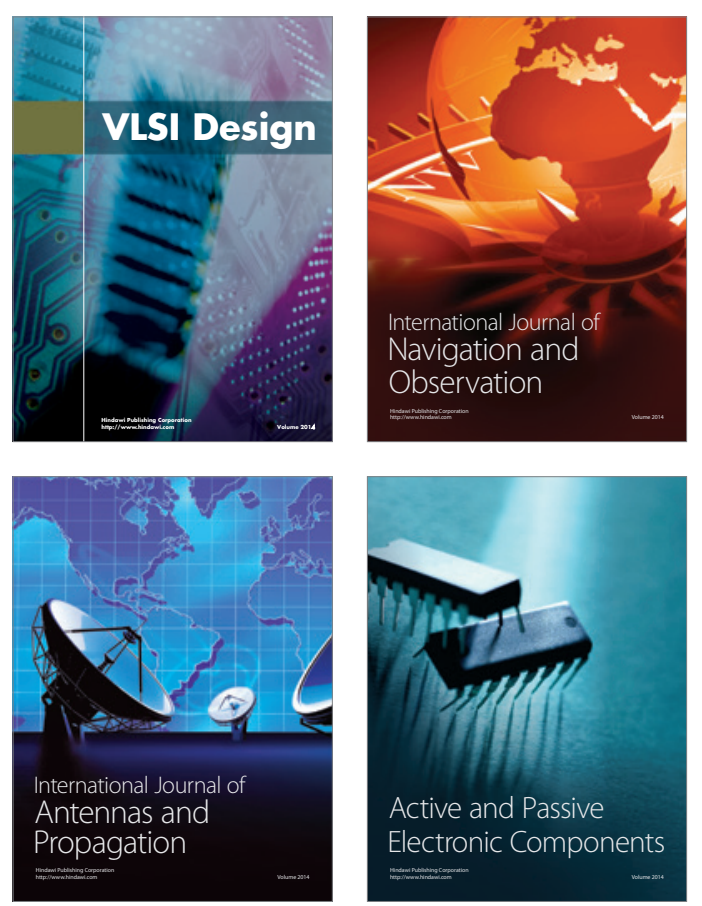
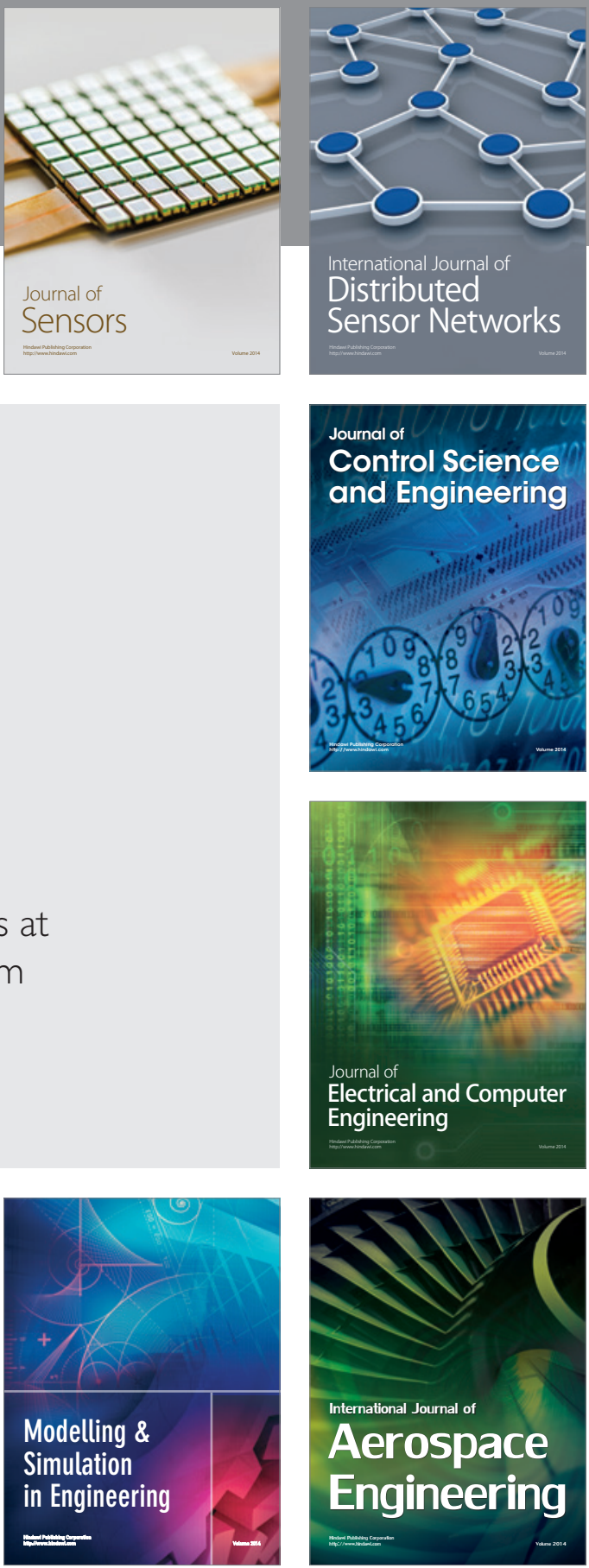

Journal of

Control Science

and Engineering
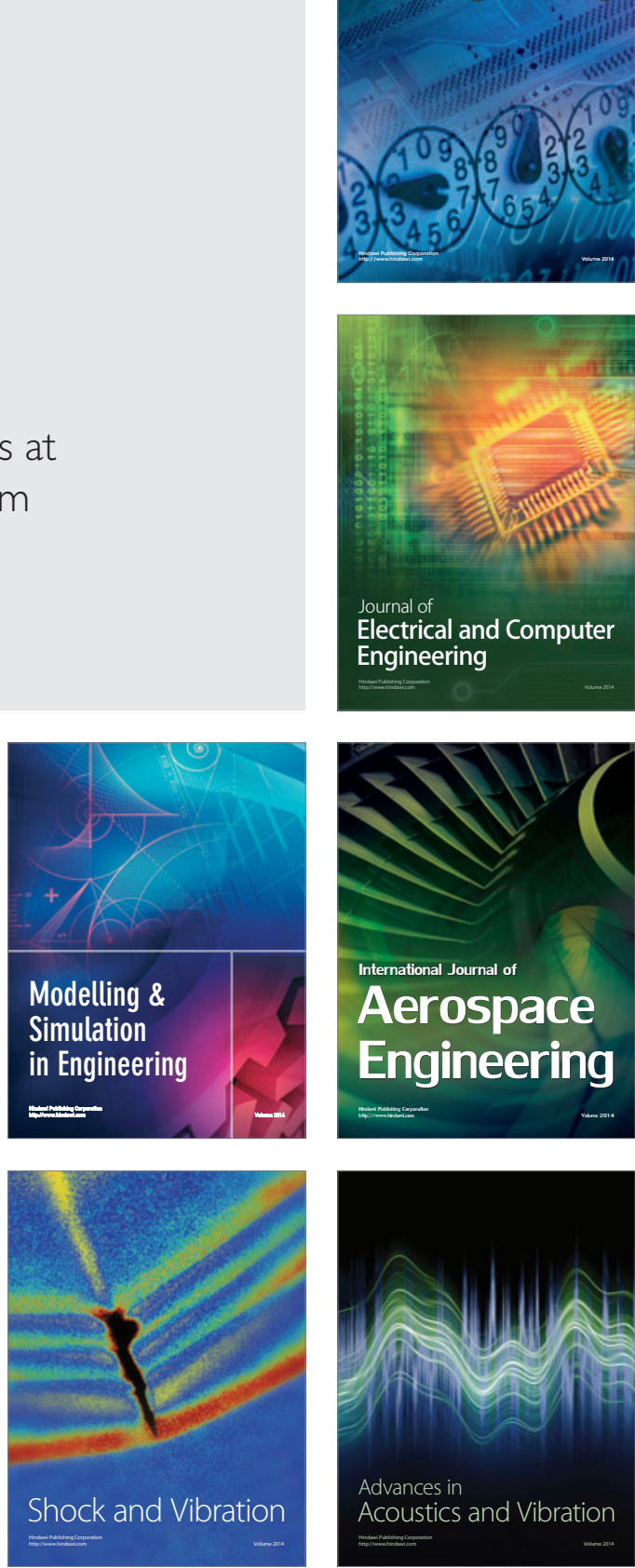